\title{
Vitamin D Supplementation Replaced Catheter Ablation in a Patient with Frequent Premature Ventricular Contractions
}

\author{
Gabriel Cismaru, Dana Pop, Dumitru Zdrenghea, Radu Rosu \\ Fifth Department of Internal Medicine, Cardiology-Rehabilitation, "Iuliu Hațieganu" University of Medicine and Pharmacy, \\ Cluj-Napoca, Romania
}

\begin{abstract}
A high premature ventricular contractions (PVC) burden can disturb the patient's condition through fatigue during exercise or palpitations. Hence, researchers started to look for treatment options that decrease PVC burden without the side effects of antiarrhythmic drugs, and vitamin $\mathrm{D}$ could be a valuable solution and safe alternative to drugs or catheter ablation for high-burden PVCs. We present the case of a 24 -year-old patient with high-burden PVC of $>25,500 / 24$ hours referred for urgent catheter ablation. Treatment with beta-blockers and calcium blockers did not reduce PVC burden. Under propafenone, there was a slight reduction in the number of PVCs to 21,200/24 hours, therefore the patient was referred for catheter ablation. As there was a vitamin D deficiency of $10.1 \mathrm{ng} / \mathrm{mL}$, an attempt of vitamin D supplementation was done, with increase of vitamin $\mathrm{D}$ to $32.1 \mathrm{ng} / \mathrm{mL}$ and decrease of PVC burden to $9,600 / 24$ hours. Further dietary supplementation increased $25-\mathrm{OH}$ vitamin D to $50.2 \mathrm{ng} / \mathrm{mL}$ and decreased the PVC burden to 119/24 hours. Consequently, catheter ablation was canceled, and the patient remained free of antiarrhythmic drugs.
\end{abstract}

Keywords: vitamin D3, 25-OH vitamin D, premature ventricular contractions, cardiac function, sunlight

\section{ARTICLE HISTORY}

Received: December 7, 2020

Accepted: March 1, 2021

\section{CORRESPONDENCE}

Gabriel Cismaru

Str. Viilor nr. 46-50

400347 Cluj-Napoca, Romania

Tel: +40 264207021

E-mail: gabi_cismaru@yahoo.com

\section{INTRODUCTION}

Vitamin D is a steroid hormone regulating the homeostasis of calcium and bone mineralization. Both hypocalcemia and vitamin D deficiency have unfavorable effects on cardiac function and have implications in the development of coronary artery disease, ${ }^{1}$ heart failure, ${ }^{2}$ left ventricular hypertrophy, ${ }^{3}$ atherosclerosis, ${ }^{4}$ and atrial fibrillation. ${ }^{5}$

Premature ventricular contractions (PVCs) are a frequent cause of palpitations and occur in almost $50 \%$ of individuals. ${ }^{6}$ PVCs are harmless when they occur in patients without heart disease. However, they can induce arrhythmogenic cardiomyopathy ${ }^{7}$ in case of high-burden PVC, or trigger ventricular tachycardia and ventricular fibrillation. ${ }^{8}$ Hence, a reduction in PVC burden may result in fewer serious arrhythmic events or arrhythmogenic cardiomyopathies. However, the reduction in PVC burden might be offset by side effects of antiarrhythmic drugs. In the Cardiac Arrhythmic Suppression Trial (CAST), encainide and flecainide reduced the PVC burden but also 


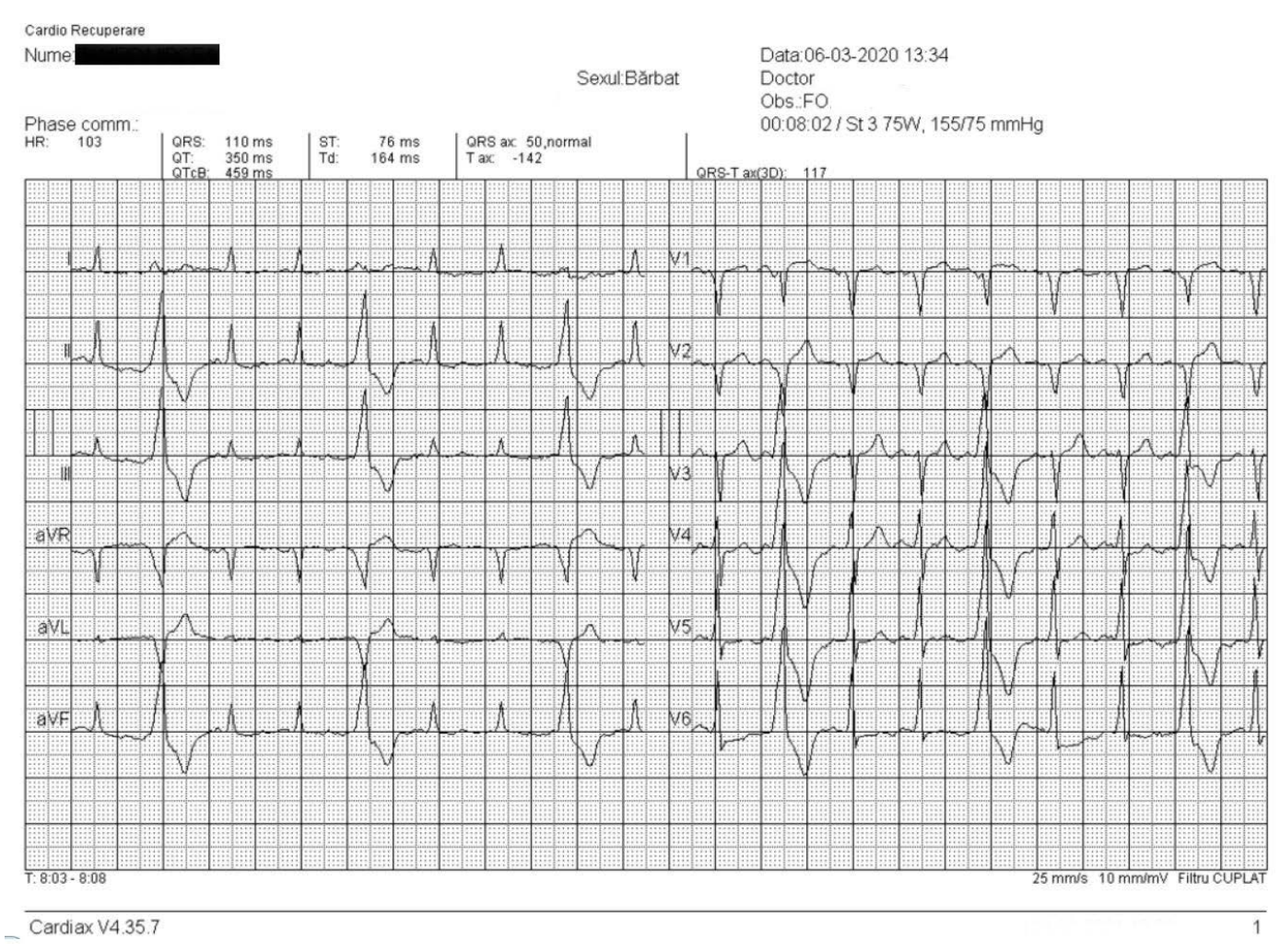

FIGURE 1. Twelve-lead ECG shows sinus rhythm with ventricular bigeminism. PVC morphology is: LBBB appearance with inferior axis and precordial transition in lead $V_{3}$

increased mortality. ${ }^{9}$ Hence, researchers started to look for other treatment options that may decrease PVC burden without the side effects of antiarrhythmic drugs. Vitamin D might be a valuable solution and safe alternative to drugs in the treatment of PVCs.

\section{CASE PRESENTATION}

A 24-year-old male patient was referred to our cardiology department for urgent catheter ablation of high-burden PVC. He presented with intermittent palpitations and mild exertional dyspnea. The physical examination showed normal findings: blood pressure of $120 / 70 \mathrm{mmHg}$, heart rate of $72 \mathrm{bpm}$, with no signs of left or right heart failure. Blood test showed normal values of complete blood count, biochemistry, and coagulation, except a low value of $25-\mathrm{OH}$ vitamin D: $10.1 \mathrm{ng} / \mathrm{mL}$ (normal values >30 ng/ $\mathrm{mL}$ ). The ECG showed frequent PVCs with a left bundle branch block morphology and inferior axis, precordial transition in V4. Figure 1 shows PVC morphology, suggestive of right ventricular outflow tract (RVOT) origin. The echocardiographic examination did not reveal significant valve disease, the heart chamber dimensions were normal, and there was no sign of arrhythmogenic cardiomyopathy, the left ventricular ejection fraction being $60 \%$. At this time, the patient was diagnosed with RVOT PVCs and insufficient vitamin D. The 24-hour Holter ECG showed a high burden of premature contractions: 25,500 PVCs/24 hours and episodes of non-sustained ventricular tachycardia (Figure 2). Beta-blockers and calcium-channel blockers were ineffective in reducing the PVC burden, therefore the patient was started on propafenone $3 \times 150$ $\mathrm{mg}$ and presented a reduction in the PVC burden to 21,200 after 2 weeks ( $17 \%$ relative reduction). As the palpitations persisted with exertional dyspnea, he was referred for catheter ablation. The laboratory tests showed insufficient levels of 25-OH vitamin D. Therefore, we decided to attempt vitamin D supplementation for 1 month before catheter ablation. After cessation of propafenone treatment, the patient was started with 2,000 U of vitamin D3 daily, without the use of any antiarrhythmic drugs. During the 2 weeks of follow-up, the patient was free of palpitations, thus he continued treatment for 2 more weeks, and 25-OH vitamin D levels had increased to $16.9 \mathrm{ng} / \mathrm{mL}$. After 2 months of daily vitamin D supplementation, the serum level of $25-\mathrm{OH}$ vitamin D level had increased to $24.7 \mathrm{ng} /$ $\mathrm{mL}$. At this point, the PVC burden decreased to $11,800 / 24$ hours (a $53 \%$ relative reduction). At the end of 5 months of vitamin D supplementation, the level of $25-\mathrm{OH}$ vitamin D had increased to $50.2 \mathrm{ng} / \mathrm{mL}$ with a decrease of PVC 


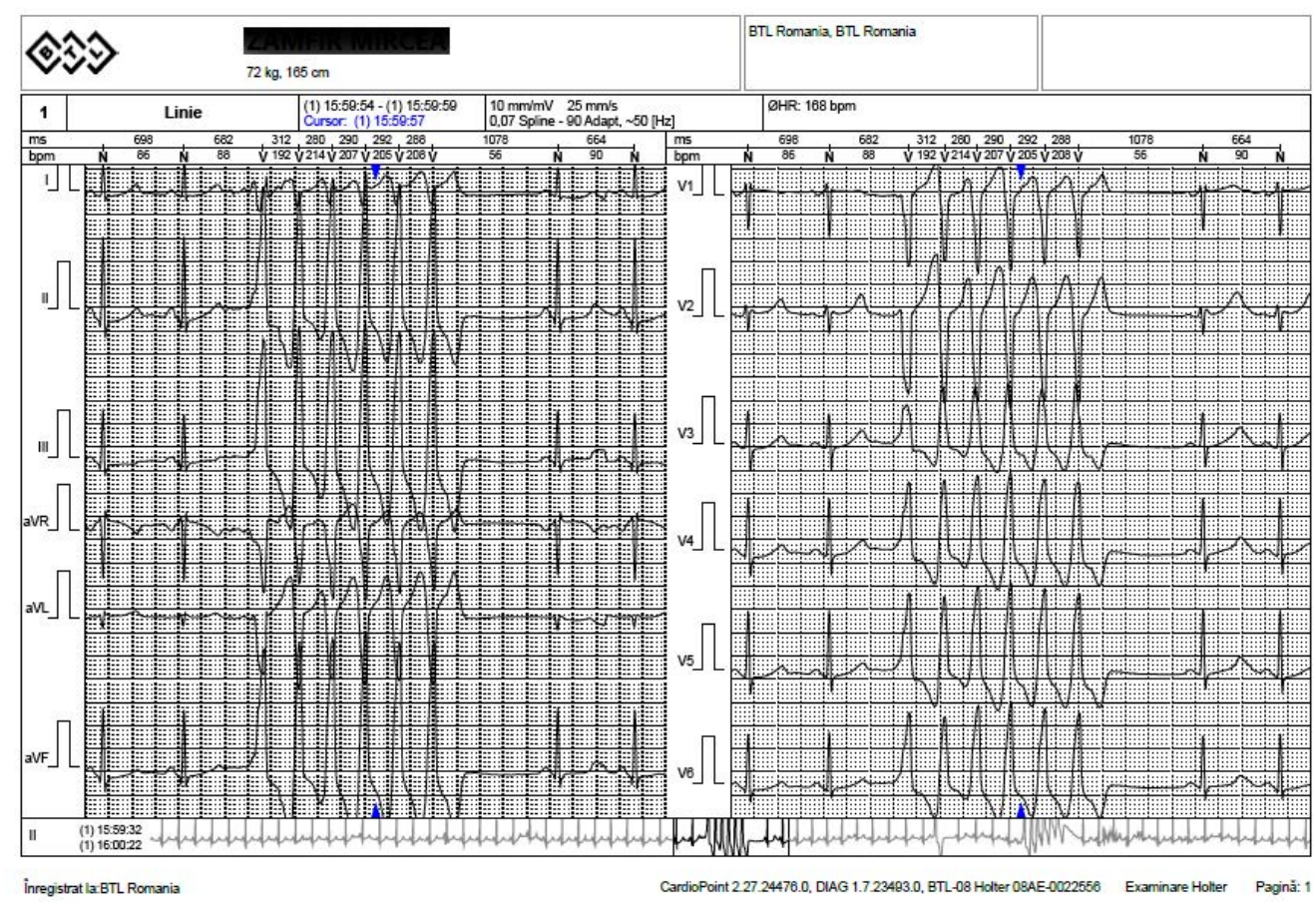

FIGURE 2. Holter ECG shows multiple PVCs with non-sustained episodes of monomorphic ventricular tachycardia. PVC burden was 25,500/24 hours

burden to 119/24 hours (a 99\% relative reduction). Figure 3 shows the reduction of PVC burden associated with the increase of 25-OH vitamin D levels. Therefore, the catheter ablation procedure was canceled, and the patient was prescribed only vitamin D supplementation without antiarrhythmic drugs. We recommended sunlight exposure during the summer season and vitamin D supplementation during the winter season (2,000 U/day). The patient agreed with the publication of his case, without images of parts of his body that could confirm his identity. The Ethics Committee of the Cardiology-Rehabilitation Hospital of Cluj-Napoca, Romania, had approved the publication of this report.

\section{DISCUSSIONS}

Our case report demonstrates that vitamin D deficiency can be responsible for high burden of PVC, and vitamin D supplementation can significantly lower this burden. RVOT PVCs have a left bundle branch block, inferior axis morphology displaying a late precordial transition in lead V4. In contrast, LVOT PVCs have an inferior axis but with an early precordial transition in V2. Both RVOT and LVOT PVCs are "benign PVCs" with a triggered activity mechanism caused by delayed after-depolarizations via cAMP and intracellular calcium overload. Medication that can directly inhibit arrhythmia pathways are calcium-channel blockers, beta-blockers, and adenosine. However, vitamin D supplementation might be a good option for this category of patients. ${ }^{10}$

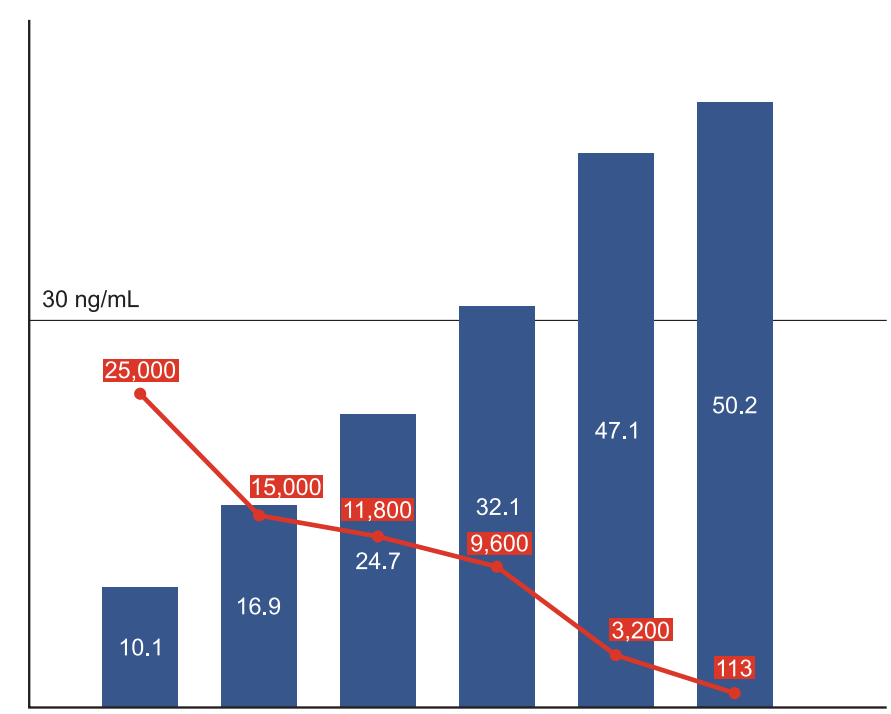

FIGURE 3. Diagram showing decrease in the number of PVCs (red line) concomitant with an increase in the plasmatic concentration of $25-\mathrm{OH}$ vitamin $\mathrm{D}$ (blue bars) 
Vitamin D deficiency, which is very prevalent in Europe, might have an important role in PVC genesis. Vitamin D3 is generated in the skin under the influence of sunlight. It has no significant biological activity, but after metabolization to $25-\mathrm{OH}$ vitamin $\mathrm{D}$ and further to $1,25-\mathrm{OH}$ vitamin D, it stimulates the absorption of calcium, phosphate, and magnesium from the intestine. The presence of vitamin D receptors in several types of cells, including cardiac myocytes, have demonstrated widespread biological effects beyond bone metabolism. In 1985, a cardiac receptor for the active metabolite of vitamin $\mathrm{D}$ was identified in the myocardial cell: the 1,25 dihydroxy-vitamin D3 receptor. The presence of vitamin D receptors together with the vitamin D3-dependent calcium-binding protein regulate the action of vitamin $\mathrm{D}$ and calcium on cardiac metabolism both in hypocalcemic and normocalcemic states. ${ }^{11}$

The prevalence of vitamin D deficiency varies according to its lower limit of $<20$ or $<30 \mathrm{ng} / \mathrm{mL}$. There is no international consensus on optimal serum values of vitamin D. Experts agree that the level needed for a good bone health should be more than $20 \mathrm{ng} / \mathrm{mL} .{ }^{12}$ Conversely, the International Osteoporosis Foundation and the Endocrine Society propose values higher than $30 \mathrm{ng} / \mathrm{mL}$. However, experts agree that there is no cut-off value of plasma levels of vitamin D in relation to extra-skeletal health. Our report shows that $30 \mathrm{ng} / \mathrm{mL}$ might be insufficient to prevent PVCs, and $50 \mathrm{ng} / \mathrm{mL}$ might be a better target for patients presenting PVCs. We do not think that a higher value $>50$ $\mathrm{ng} / \mathrm{mL}$ can bring a more relevant benefit, but this should be tested and proven in large clinical studies.

In Romania, due to its latitude $\left(48^{\circ} 15^{\prime} \mathrm{N}\right.$ to $\left.43^{\circ} 40^{\prime} \mathrm{N}\right)$, there is a seasonal variation of vitamin D levels: it increases from April to September and decreases from October to March. ${ }^{13}$ Our patient had presented with vitamin D deficiency, which might be variable according to different seasons of the year. The first value of $25-\mathrm{OH}$ vitamin D of $10.1 \mathrm{ng} / \mathrm{mL}$ was without any vitamin D supplementation; the following values were detected after the administration of vitamin D supplements, the highest level being $50.2 \mathrm{ng} / \mathrm{mL}$. It was demonstrated that Caucasians, after body exposure to sunlight for 10 to 15 minutes, can generate approximately 20,000 U of vitamin D. Therefore, our patient was advised to acquire sunlight exposure during summer months and to take vitamin D supplements during the winter. We used 2,000 U/day vitamin D supplementation to increase the levels of $25-\mathrm{OH}$ vitamin $\mathrm{D}$. A better option for a faster effect might be 5,000 U/day. We preferred the low dose in order to prevent vitamin $\mathrm{D}$ toxicity, which is however a rare finding and needs serum levels higher than $>150 \mathrm{ng} / \mathrm{mL}$.
In the presented case, the level of ionized calcium was normal, even though vitamin D was deficient. Therefore, frequent PVCs cannot be attributable to hypocalcemia, but rather to low levels of vitamin D. Many studies have shown that even if there is a clear relationship between vitamin $\mathrm{D}$, parathormone, and calcium homeostasis, there is a weak correlation between vitamin D levels and ionized calcium levels. ${ }^{14-17}$ When vitamin $\mathrm{D}$ is reduced, active calcium absorption is also reduced, in spite of normal ionized calcium levels. Therefore, calcium-induced calcium release from intracellular stores could also be reduced.

In general, the success rate of radiofrequency ablation in PVCs originating in the RVOT is high. In most studies, a success rate of $>80 \%{ }^{18}$ has been reported with a low long-term recurrence rate of $<5 \% .{ }^{19}$ Catheter ablation is generally used when the patient is symptomatic, develops arrhythmic cardiomyopathy, or is at risk of developing arrhythmic cardiomyopathy (PVC burden of $>20-24 \%$ ). ${ }^{20}$ The change in PVC burden observed in our patient cannot be attributed to spontaneous variability, defined as less than $20 \%$ reduction in PVCs. A positive response to treatment in patients with PVCs can be defined as a reduction of PVC burden by more than $70 \% .{ }^{21}$ In our patient, the reduction percentage was $61.6 \%$ when 25 -OHvitamin D had reached $30 \mathrm{ng} / \mathrm{mL}$ and more than $99 \%$ with an increase to $50 \mathrm{ng} / \mathrm{mL}$. Therefore, we believe that vitamin D supplementation is effective in patients with high-number PVCs, without the need of antiarrhythmic drugs or catheter ablation, and the optimal level of $25-\mathrm{OH}$ vitamin $\mathrm{D}$ is close to $50 \mathrm{ng} / \mathrm{mL}$.

\section{CONCLUSIONS}

Our report demonstrates that vitamin D deficiency can be a cause of high-burden PVCs. Vitamin D supplementation is an easy and effective therapeutic option, with significant reduction in PVC burden. Furthermore, antiarrhythmic drugs and catheter ablation might be avoided in this scenario.

\section{CONFLICT OF INTEREST}

Nothing to declare.

\section{REFERENCES}

1. Rocchiccioli S, Andreassi MG, Cecchettini A, Carpeggiani C, L'Abbate A, Citti L. Correlation between vitamin D binding protein expression and angiographic-proven coronary artery disease. Coron Artery Dis. 2012;23:426-431. doi: 10.1097/ MCA.obo13e328358781c. 
2. Patel R, Rizvi AA. Vitamin D deficiency in patients with congestive heart failure: mechanisms, manifestations, and management. South Med J. 2011;104:325-330. doi: 10.1097/ SMJ.ob013e318213cf6b.

3. O'Connell TD, Berry JE, Jarvis AK, Somerman MJ, Simpson RU. 1,25-Dihydroxyvitamin D3 regulation of cardiac myocyte proliferation and hypertrophy. Am J Physiol. 1997;272:H1751-H1758. doi:10.1152/ajpheart.1997.272.4.H1751.

4. Surdu AM, Pînzariu O, Ciobanu DM, et al. Vitamin D and Its Role in the Lipid Metabolism and the Development of Atherosclerosis. Biomedicines. 2021;9:172. doi: 10.3390/ biomedicines9020172.

5. Demir M, Uyan U, Melek M. The effects of vitamin D deficiency on atrial fibrillation. Clin Appl Thromb Hemost. 2014;20:98103. doi: 10.1177/1076029612453762.

6. Barret PA, Peter CT, Swan HJ, Singh BN, Mandel WJ. The frequency and prognostic significance of electrocardiographic abnormalities in clinically normal individuals. Prog Cardiovasc Dis. 1981;23:299-319. doi: 10.1016/0033-0620(81)90018-9.

7. Maggioni AP, Zuanetti G, FranzosiMG, et al. Prevalence and prognostic significance of ventricular arrhythmias after acute myocardial infarction in the fibrinolytic era. GISSI-2 results. Circulation. 1993;87:312-322. doi: 10.1161/01.cir.87.2.312.

8. Jimenez RA, Myerburg RJ. Sudden cardiac death. Magnitude of the problem, substrate/trigger interaction, and populations at high risk. Cardiol Clin. 1993;11:1-9.

9. The Cardiac Arrhythmia Suppression Trial (CAST) Investigators. Preliminary report: effect of encainide and flecainide on mortality in a randomized trial of arrhythmia suppression after myocardial infarction. $\mathrm{N}$ Engl J Med. 1989;321:406-412. doi: 10.1056/NEJM198908103210629.

10. Cismaru G, Gurzau D, Fringu F, Martis A, Caloian B, Comsa H. Vitamin D supplementation with Cardiac Rehabilitation reduces the number of RVOT Premature Ventricular Contractions. Balneo Research Journal. 2020;11:566-568.

11. Weishaar RE, Simpson RU. Involvement of vitamin D3 with cardiovascular function. II. Direct and indirect effects. Am J Physiol. 1987;253:E675-E683. doi: 10.1152/ ajpendo.1987.253.6.E675.

12. Ross AC, Manson JE, Abrams SA, et al. The 2011 report on dietary reference intakes for calcium and vitamin $\mathrm{D}$ from the Institute of Medicine: what clinicians need to know. J Clin Endocrinol Metab. 2011;96:53-58. doi: 10.1210/jc.2010-2704.

13. Chirita-Emandi A, Socolov D, Haivas C, et al. Vitamin D status: a different story in the very young versus the very old Romanian patients. PLoS One. 2015;10:1-14. doi: 10.1371/ journal.pone.0128010.

14. Steingrimsdottir L, Gunnarsson O, Indridason OS et al. Relationship between serum parathyroid hormone levels, vitamin D sufficiency and calcium intake. JAMA. 2005;294:2336-2341. doi: 10.1001/jama.294.18.2336.

15. Huss L, Butt S, Borquist S et al. Serum levels of vitamin D, parathyroid hormone and calcium in relation to survival following breast cancer. Cancer Causes Control. 2014;25:11311140. doi: 10.1007/s10552-014-0413-3.

16. Vierucci F, Pistoia MD, Fanos M, et al. Vitamin D status and predicitors of hypovitaminosis D in Italian children and adolescents: a cross-sectional study. Eur J Pediatr: 1-11. doi: 10.1007/s00431-013-2119-z.

17. Azab SF, Saleh SH Elsaeed WF, et al. Vitamin D status in diabetic Egyptian children and adolescents: a case-control study. Italian Journal of Pediatrics. 2013;39:73. doi: 10.1186/18247288-39-73.

18. Coggins DL, Lee RJ, Sweeney J, et al. Radiofrequency catheter ablation as a cure for idiopathic tachycardia of both left and right ventricular origin. J Am Coll Cardiol. 1994;23:1333-41. doi: 10.1016/0735-1097(94)90375-1.

19. Krittayaphong R, Sriratanasathavorn C, Dumavibhat C, et al. Electrocardiographic predictors of long-term outcomes after radiofrequency ablation in patients with right-ventricular outflow tract tachycardia. Europace. 2006;8:601-6. doi: 10.1093/europace/eulo67.

20. Baman TS, Lange DC, Ilg KJ, et al. Relationship between burden of premature ventricular complexes and left ventricular function. Heart Rhythm. 2010; 7:865-9. doi: 10.1016/j. hrthm.2010.03.036.

21. Gudbjamaron S. Dynami The ESVEM Investigators. Determinants of predicted etflcacy uf antlarrhythmic drugs m the elrctrophyslologic versus electrocardiopraphic momcoring trial. Circulation. 1993;87:323-329. 